\section{The impact of cross-cultural communication on collective efficacy in NCAA basketball teams}

\author{
Robin Bell and Carlos Fernández Riol
}

University of Worcester, UK
International Journal of Cross Cultural Management 2017, Vol. 17(2) 175-195 (C) The Author(s) 2017 Reprints and permissions: sagepub.co.uk/journalsPermissions.nav DOI: $10.1177 / 1470595817702678$ journals.sagepub.com/home/ccm

@SAGE

\begin{abstract}
This research contributes to the knowledge and theory on cross-cultural communication by investigating the impact of cross-cultural communication competence on the collective efficacy of multicultural National Collegiate Athletic Association basketball teams. Data was collected from 140 US National Collegiate Athletic Association basketball coaches via the Cross-Cultural Communication Competence Questionnaire and the Collective Efficacy Questionnaire for Sports. Principle component analysis was conducted on the data, revealing that the cross-cultural communication competence and collective efficacy of basketball teams are multidimensional. The hypothesized relationship between cross-cultural communication competence and collective efficacy was confirmed and statistically measured through regression analysis. It was found that four of the cross-cultural communication competence dimensions produced by the principle component analysis exhibited a significant positive relationship with one of the two dimensions within collective efficacy. Given the well-supported relationship between collective efficacy and team performance in business, this study produces important implications for scholars and practitioners working with multicultural sporting teams.
\end{abstract}

\title{
Keywords
}

Basketball, cross-cultural communication, cross-cultural management, collective efficacy, International Management, NCAA

\section{Introduction}

Increased focus on diversity within the National Collegiate Athletic Association (NCAA), which organizes athletic programmes and collegiate-level sports in many higher education institutions in the United States (and some in Canada), has produced multicultural college basketball teams. NCAA basketball teams in division I and division II are made up of over 20,000 men and women

\section{Corresponding author:}

Robin Bell, University of Worcester, MHI005, Infirmary Walk, Worcester, Worcestershire WRI 3AS, UK. Email: r.bell@worc.ac.uk 
athletes and over 1300 head coaches. NCAA figures indicate that many cultural ethnicities and identities are represented among players. In 2013, the top four self-identified categories of players were (in descending order) 'Black', 'White', 'non-resident alien (meaning a non-citizen)' and 'two or more races'. While the teams themselves may be diverse, over three-quarters of NCAA division I and II head coaches categorize themselves as White males (NCAA, 2015a), meaning that inevitably these coaches are communicating across their own culture.

Diversity within the NCAA highlights the need for effective cross-cultural management by coaches. Its athletes are all young adults who have recently completed high school, and while they may be playing on teams with individuals of the same gender and similar age, they may have little experience working together on a culturally diverse team. Indeed, these new team members face the same issues with effective group work across cultures as all incoming freshman; namely, they hail from relatively homogenous communities and thus often arrive on campus with little experience in the dynamics of working on a multicultural team (Chapman and Van Auken, 2001; Orfield, 2009).

Thus, an important role of the NCAA coach is to effectively communicate across cultures to create a well-managed team, a team with a collective identity that supersedes individual identity issues and leads the team to accomplish its goal of winning games. The literature has highlighted the importance of cross-cultural communication skills for managers of diverse and multicultural teams, and the need for collective efficacy among members of successful teams has also been established (Chmielecki, 2012; Mor-Barak, 2011; Stockdale and Crosby, 2004). To effectively manage a multicultural team, managers need to develop diversity-related competencies and raise levels of cultural understanding and awareness (Lane et al., 2004). This work examines the impact of NCAA basketball coaches' cross-cultural communication competency on the collective efficacy of the team in order to show how cross-cultural communication impacts on specific dimensions of collective efficacy. Because collective efficacy has a direct relationship with team performance (Campion et al., 1996; Gibson, 1999), this research highlights the specific ways in which cross-cultural communication competencies affect NCAA coaches, who are managers of novice multicultural teams.

Past research has effectively used data on sporting teams as a proxy for wider organizational behaviour, with basketball being used by Berman et al. (2002) to study the impact of tacit group knowledge on competitive advantage, Staw and Hoang (1995) to look at sunk costs in decisionmaking and Pfeffer and Davis-Blake (1986) to examine administrative succession, and as such, this research will examine both wider organizational and sports literature.

This research will review the literature concerning cross-cultural communication competency, management of multicultural teams and collective efficacy. It then will put forward the research and methods used to answer the question, 'How does the cross-cultural communication competency of NCAA basketball coaches impact their teams' collective efficacy?' The results are presented and implications discussed.

\section{Literature review}

\section{Cross-cultural communication competency and cross-cultural team management}

Cross-cultural communication competence. Communication is a convergent process in that it aligns a group of individuals around a common objective, and the process can decrease with increased cultural diversity (Stahl et al., 2010). Culture, that is, a commonly held body of beliefs and values, 
and communication can be seen to have an interdependent relationship (Hall, 1959; Hofstede, 1980). Just as cultural norms influence the way people communicate, the interpersonal communication patterns of a society influence its culture (Gudykunst, 1997). Cross-cultural communication occurs both cross-nationally and intra-nationally. It thus refers to communication between individuals from different countries, or it may refer to communication between individuals from the same country but from different 'co-cultures', with different ethnic identities and traditions (Nixon and Dawson, 2002).

While communication ideally occurs in an ongoing feedback loop, being unable to understand and assess the information communicated properly can lead to breakdowns in communication across cultures (Hurn and Tomalin, 2013). Thus, an argument has been made within the management literature for effective cross-cultural communication competency in management. Ricard (1993: 7) defined cross-cultural communication competence as 'the ability of an individual or a group to achieve understanding through verbal or non-verbal exchange and interaction between cultures'. Cross-cultural communication competence requires communication skills, behavioural skills like charisma and empathy, and respect, openness and curiosity towards other cultures (Black and Gregersen, 1999; Deardorff, 2011; Gudykunst, 1998). Wiseman et al. (1989) suggested that high levels of cross-cultural communication competence require the ability to acknowledge other cultures' decision-making approaches and to adapt communication style.

Researchers have approached the measure and analysis of cross-cultural communication competency by looking at behavioural dimensions (Ruben, 1976) and intercultural effectiveness dimensions (Abe and Wiseman, 1983; Cui and Awa, 1992). Matveev (2002) developed a comprehensive model to examine the cross-cultural communication competence of managers working on multicultural teams that analysed effectiveness at communicating with other cultures based on four underlying factors: interpersonal skills, team effectiveness, cultural uncertainty and cultural empathy.

Cross-cultural management. Blasco et al. (2012) have put forth that managers of multinational organizations should possess a holistic 'global mindset'. The skills and traits required of a global mindset include adaptability, openness, alacrity to engage and communicate with other cultures, and an ability to see things from another perspective (Levy et al., 2007). Mor et al. (2013) found that 'cultural perspective taking' improves managerial performance when working with international teams. When managing a team, MacNab and Worthley (2013) maintain that crosscultural managers must be aware of stereotypes they hold about other cultures and advocate appropriate training to give managers the skills to recognize and control for these cultural assumptions. Managers need to have a basic knowledge of the cultures with which they are interacting and must understand their team members' personalities and behaviour patterns in conflict situations (Triandis and Singelis, 1998).

Plessis (2012) argues that the managers of multicultural teams must possess a different skill set than those required for general teamwork because multicultural team settings pose a unique set of challenges arising from cross-cultural conflict, which must be effectively managed. Effective crosscultural management skills have been shown to lessen the negative effects of unmet expectations that recent expatriates may feel as they adjust to a new job role (Majahan and De Silva, 2012). Managers of multicultural teams must also be concerned with social integration, that is, "the attraction to the group, satisfaction with other members of the group, and social interaction among group members' (O'Reilly et al., 1989: 2). Trust and cohesion, which can also impact collective efficacy, are part of social integration. In addition, as trust in a manager has been shown to positively 
influence team performance (Dirks, 2000), cross-cultural management must be concerned with not only fostering integration across the team but also upwards to establish trust between the individuals on the team and the manager.

These competencies are necessary whether the differences in team make-up are due to crossnational or intra-national cultural differences, as Tung (2008) has argued that intra-national differences among individuals on a team are as significant as cross-national cultural differences. Stahl et al. (2010) found that the type of diversity (cross-national or intra-national) did not impact the relationship between a team's cultural diversity and its social integration.

Effective communication is a key factor in predicting the performance of multicultural teams (Shonk, 1982). Wheelan (1999) argues that a business team leader must have an effective communication style in order to have high-quality team performance and Kieffer (1997) states that poor communication skills could ruin a team's performance. Cross-cultural communication competence is the essential component to increase a manager's ability to transcend the challenges faced by multicultural teams and elicit high-quality team performance (Matveev and Nelson, 2004). Matveev and Nelson (2004) demonstrated that cross-cultural communication competence accounts for 20 per cent of the variance in the performance level of multicultural teams.

However, it should be noted that while the literature has examined the impact of cross-cultural communication competency on management, different communication styles within cultures also have an impact on preferences for leadership styles between cultures. Differences in levels of democratic verses autocratic leadership and communication and different preferences in levels of support and feedback communicated from management have been identified (Chelladurai et al., 1987, 1988). Wheelan et al. (1998) argue that a deeper understanding of the intercultural communication process is vital to achieving high level of performance within culturally diverse teams, but it must also be acknowledged that there may be no perfect solution to managing multicultural teams with different management preferences.

\section{Collective efficacy and multicultural team performance}

An effective manager builds a team that works together towards a collective goal. Bringing together individuals into an effective team is impossible without the team members sharing some form of collective identity, and this presents a greater challenge when the team members possess different morals and ideals (Chevrier, 2009). Individual differences in norms, behaviour and communication styles can cause misunderstanding, conflict and poor team performance (Gong et al., 2001). Research has shown different effects of cultural diversity on team performance. Some studies have found that cultural diversity can improve team performance (Ely and Thomas, 2001; Mor-Barak, 2011; Stockdale and Crosby, 2004). Matveev and Nelson (2004), among others, found that multicultural teams may experience interaction problems.

The ambiguity remains when the focus is refined towards sporting teams. Previous studies examining European football leagues have found differing results regarding the impact of cultural diversity on sport team performance. With specific regard to coaching and managing a team, Maderer et al. (2014) found that a coaches' intercultural coaching experience negatively impacted their teams' performance. The authors also examined other European football (all German Bundesliga) related papers to examine other findings of the impact of cultural diversity on a team's success, finding mixed results with some (e.g. Andresen and Altmann, 2006; Wulf and Hungenberg, 2006) showing a positive impact and others (Brandes et al., 2009; Gaede et al., 2002; Teichmann, 
2007) showing no impact. Prinz and Wicker (2012) found that different ethnicities within a team made no impact on Tour de France team performance.

The negative impacts of cultural diversity on team performance may be in explained in part by similarity attraction theory, in which individuals are attracted to working with others who they find similar to themselves (Williams and O'Reilly, 1998). These impacts may also be somewhat explained by social identity and social categorization theory, in which individuals categorize themselves into groups, whom they favour, and view others as 'outsiders', who they may stereotype and judge more harshly (Tajfel, 1982). Positive impacts of cultural diversity, conversely, may be somewhat explained by information-processing theory, in which cultural diversity contributes positively to a team by bringing in a variety of perspectives, networks and approaches to problemsolving (Cox, 1994; Stahl et al., 2010). The process by which these different values and ideas are juxtaposed against each other is referred to as divergent processes, which increase with greater cultural diversity and can be managed to increase creativity but can also be sources of conflict (Stahl, et al., 2010). Bell (2007) and Joshi and Roh (2009) have suggested that contextual variables may moderate the relationship between a team's cultural diversity and its performance.

Collective efficacy refers to a 'group's shared belief in its conjoint capability to organize and execute the courses of action required to produce given levels of attainment' (Bandura, 1997: 477). Developing cohesion, commitment and a common identity within a group is a convergent process argued by Stahl et al. (2010) to positively impact to group performance and goal attainment. Past research has emphasized collective efficacy as a key determinant of team member motivation when facing failure (Greenlees et al., 1999). Researchers have found a link between a group's perceived collective efficacy and its interdependence, cohesion, resilience, motivation and morale (Bandura, 2001; Katz-Navon and Erez, 2005). If culture provides a source of identity for its members (Stahl, et al., 2010), then collective efficacy can be argued to be a proxy for culture within a group setting.

Collective efficacy can be argued to be an important factor in basketball teams. Berman et al. (2002) argued that basketball requires high levels of 'group tacit knowledge' among players in order to unconsciously communicate in a manner required to successfully play basketball, a sport requiring particularly high levels of interdependence and coordination (Keidel, 1985). Weick and Roberts (1993: 358) defined this as individuals interacting as though they were part of a 'single transactive memory system, complete with differentiated responsibility for remembering different portions of common experience'.

Research has found a positive relationship between collective efficacy and team performance in a variety of team settings (Campion et al., 1996; Gibson, 1999 Heuzé et al., 2006; Myers et al., 2004; Ramzaninezhad et al., 2009). Gully et al. (2002) statistically measured this correlation and concluded that collective efficacy accounts for 21 per cent of the variance in team performance.

A number of sport-specific measurement instruments have been developed to measure collective efficacy (Magyar et al., 2004; Myers et al., 2004). Short et al. (2005) developed the first multisporting discipline theoretical framework to measure collective efficacy across multiple sports, based on five interrelated factors: ability, effort, preparation, persistence and unity.

\section{NCAA basketball}

\section{Student NCAA team composition}

The NCAA is an American rules-making body and a scholarship organization for college sports mainly in the United States, with some Canadian member colleges. Over 650 colleges have NCAA 
division I or II male and female basketball teams, each managed by a head coach. While the teams are increasingly diverse, with less than half of the players identifying as White Americans, 76 per cent of teams have a White American head coach. NCAA basketball coaches are thus very likely to be coaching a team of individuals from cultures different from their own and must find a way to build trust and form a cohesive team. In addition, the majority of their incoming players have come from relatively homogenous communities and may be either unfamiliar with or inexperienced with working constructively with peers from different backgrounds (Orfield, 2009).

The need for effective cross-cultural management by coaches is further emphasized by the nature of NCAA teams. Each year sees some team members departing after graduation and others joining the team as incoming freshmen. Team members are bound by NCAA rules to play for no more than 4 years (which must be completed within the first 5 years after full-time study begins) and must begin their college career after graduating high school (NCAA, 2015b). Thus, teams consist of entry/early-level 'employees', with no mid- or senior level 'staff' of more than 4 years on the team to maintain continuity or guide the newer team members through the team-building process. Nor do the team members have any professional experience, as all division I and II team members enter college after completing high school as certified amateurs, without professional experience in either the sport or any commercial endorsements, per the NCAA Eligibility Center (NCAA, 2015b).

NCAA coaches must overcome these issues, as well as cultural issues, to make a team perform cohesively in an environment in which a team's success will be dependent almost completely upon its people, rather than any advantages from technology or equipment. NCAA basketball coaches control the team's strategies, the players' court time and must ensure cohesion among players in high-stress situations (Wright et al., 1995). One of the tasks of the coach must be to lead the individuals to overcome any predominance of their cultural identity, which will likely be detrimental to the team's cohesion (Van Der Zee et al., 2004), and work towards the formation of new social relations that will contribute to a new group identity. The importance of the coach to manage a group of multicultural players into a team with collective efficacy is paramount to success. Judgements of collective efficacy by NCAA coaches and team members were shown to be positive predictors of team performance (Watson et al., 2001).

\section{Research aim and question}

This research investigates the relationship between the cross-cultural communication competence of NCAA basketball coaches and collective efficacy of multicultural NCAA basketball teams. Previous research on the predictors of collective efficacy indicates that leadership style (Chen and Bliese, 2002) and relationships among team members (Larson and LaFasto, 1989) are antecedents of collective efficacy. Given the vital role that communication competence has on leadership style (Madlock, 2008), a sporting coach's communication competence is hypothesized to be an important predictor of collective efficacy. Among managers' functions are to clarify roles and provide social and psychological support, likely indicating that the manager's communication skills affect collective efficacy (Yukl, 2012). Research has shown both positive and negative impacts of cultural diversity on team performance, which suggests that external factors, such as management, can impact collective efficacy and overall performance.

Sports psychologists have emphasized communication between players and their coaches as greatly relevant to a team's success (Yukelson, 1997). This research seeks to determine how and to what extent a sporting coach's cross-cultural communication competence will predict the collective 
efficacy of a multicultural basketball team of players of the same gender and of similar age, athletic ability and scholastic aptitude. It is hypothesized that the cross-cultural communication competence of NCAA division I and II basketball coaches will positively impact collective efficacy, with some dimension of collective efficacy being more impacted than others.

\section{Research methodology}

The research measured both cross-cultural communication competence and collective efficacy using two separate questionnaires within the same online survey.

Cross-cultural communication competence was measured using the 7-point, 23-item CrossCultural Communication Competency (CCC) Questionnaire developed by Matveev (2002) based on his $3 \mathrm{C}$ model. It includes elements such as 'I am flexible when working with people from different countries as I acknowledge differences in values and beliefs among cultures' or 'establishing a good relationship with people from other countries is difficult'. The elements are not business-management specific and can be used in a variety of management and coaching environments. This measurement instrument has been developed and tested within the business literature to investigate the relationship between cross-cultural communication competence and multicultural team performance (Congden et al., 2009; Matveev and Nelson, 2004). It has been found to produce a high level of internal consistency in the results obtained (Matveev and Nelson, 2004) and has suggested a significant relationship between CCC scores and multicultural team performance scores (Congden et al., 2009; Matveev and Nelson, 2004). The CCC questionnaire includes several reverse-worded items to minimize answering inertia, reduce boredom and ensure control for acquiescent response sets (Schriesheim and Hill, 1981).

Collective efficacy was measured using the 10-point, 20-item Collective Efficacy Questionnaire for Sports (CEQS) developed by Short et al. (2005). The CEQS requires the participant to rate his confidence in the team's ability in terms such as 'maintain effective communication' or 'persist when obstacles are present'. It was specifically developed to be used across a range of sports research and was tested with a validation sample of 286 college-aged student athletes. It was found that the measurement instrument showed a high level of internal consistency and the subscales within the measurement instrument were correlated with each other and with the total score (Short et al., 2005).

Both the CCC questionnaire and the CEQS use multi-item composition for each dimension of the cross-cultural communication competence and collective efficacy measurements to minimize itemcontext effects and to ensure measurement validity (Tourangeau and Rasinski, 1988).

Links to the online survey were sent to NCAA division I and II head coaches. An explanation of the study was presented with each of the questionnaires and participants were guaranteed confidentiality for their responses.

A total of 140 NCAA basketball team coach responses were included in the final study. While some researchers argue that organizational research should take measures to reduce single respondent bias (see Kumar et al., 1993), the nature of the NCAA teams meant that the organizational and management structure of the teams is not as layered as it is in many organizations. Kalmi and Sweins (2010) argue that a single, well-informed source of data is more effective than lessinformed respondents. Since head coaches have the most information on the team and all the players are relative newcomers to NCAA basketball, head coaches can be argued to be the best sources of information on the team. To reduce common method variance ex ante, respondents were assured 
Table I. Breakdown of research participants.

\begin{tabular}{|c|c|c|c|}
\hline & Participants (per cent) & Mean age (years) & $\begin{array}{c}\left.\text { Gender: Men ( }{ }^{\hat{*}} \text { per cent }\right) / \\
\text { Women ( } \$ \text { per cent })\end{array}$ \\
\hline Men's basketball & $80(57.1)$ & $47.0(\mathrm{SD}=9.9)$ & 78 ๙ิ (97.5)/2 9 (2.5) \\
\hline Women's basketball & 60 (42.9) & $44.9(\mathrm{SD}=10.2)$ & 32 क (53.3)/28 (46.7) \\
\hline Total sample & $140(100)$ & $46.1(S D=10.0)$ & 110 o $(78.6) / 30$ \& (21.4) \\
\hline
\end{tabular}

Note: SD: standard deviation.

both that their anonymity would be maintained and that there were no 'right or wrong' answers (Chang et al., 2010; Podsakoff et al., 2003), the questions were checked to ensure they reduced ambiguity (Lindell and Whitney, 2001; Podsakoff et al., 2003) and the scales for each of the question types were different (7 point vs 10 point) (Chang et al, 2010; Parkhe, 1993). Further ex post discussion of these biases will follow in the principle component analyses sections.

College-level basketball teams provided an appropriate setting to study the research question, as each team is guided by NCAA rules and guidelines and the teams have the same performance objectives. In addition, the teams are all made up of members of similar age, all are recognized as outstanding athletes, and all have achieved a minimum grade point average to be eligible to play, and team members are of the same gender, lessening the impact of some 'surface-level' aspects of the cultural diversity (Mannix and Neale, 2005) of the team members and allowing for the diversity in teams to be due in greater degree to ethnicity, nationality and cultural mindsets. In addition, NCAA rules mandate that its division I and II athletes are amateurs and does not allow for external employment, such that most of the athletes are engaged in similar academic and extracurricular experiences during their tenure as NCAA basketball players.

The respondents included 80 coaches of men's teams and 60 coaches of women's teams. The mean age of the respondents was 46.1 years $(\mathrm{SD}=10.0)$. The respondents included 110 males and 30 females. The demographics of NCAA coaches may explain the greater rate of male participation in the survey, as 99 per cent of male collegiate basketball teams and 42 per cent of female collegiate basketball teams have male head coaches (NCAA, 2015a). All but five respondents were US citizens. Coaches were asked if their current teams included foreign players, and those responses from coaches without multicultural teams were removed from the data analysis. As such, the data would represent only coaches of teams with both cross-national and intra-national diversity (Table 1).

\section{Data analysis and results}

In the first stage of the data analysis, two sets of data produced from the two questionnaires were subjected to principle component analysis to reduce the number of multiple indicator measures (latent variables) by identifying smaller variable groups (factors), which are correlated through a common thread. This was conducted in order to validate the measurement instruments in the basketball environment.

A principal component analysis with varimax rotation was conducted on the data collected. The Kaiser eigenvalues-greater-than-one rule was used to extract the relevant components for each questionnaire (Kaiser, 1960). In order to obtain clear factor structures, only items with a minimum 
Table 2. Total variance explained in principle component analysis of scale items measuring cross-cultural communication.

\begin{tabular}{|c|c|c|c|c|c|c|}
\hline \multirow[b]{2}{*}{ Factor } & \multicolumn{3}{|c|}{ Initial eigenvalues } & \multicolumn{3}{|c|}{ Rotation sums of squared loadings } \\
\hline & Total & Per cent of variance & Cumulative per cent & Total & Per cent of variance & Cumulative per cent \\
\hline I & 3.328 & 22.187 & 22.187 & 2.039 & 13.593 & 13.593 \\
\hline 2 & $\mathrm{I} .738$ & 11.585 & 33.772 & 2.025 & 13.498 & 27.091 \\
\hline 3 & $\mathrm{I} .376$ & 9.175 & 42.947 & 1.737 & 11.578 & 38.669 \\
\hline 4 & 1.228 & 8.187 & 51.133 & 1.551 & 10.342 & 49.011 \\
\hline 5 & 1.121 & 7.475 & 58.608 & 1.440 & 9.597 & 58.608 \\
\hline
\end{tabular}

Note: Extraction method is principle component analysis.

loading of 0.5 were retained. Finally, regression analysis was conducted to examine the impact of cross-cultural communication competence on collective efficacy.

\section{Principle component analysis of CCC questionnaire data}

A Kaiser-Meyer-Olkin (KMO) test was conducted and produced a measure of 0.689 , confirming that the data sample was ok for principle component analysis (Kaiser, 1974). Scale purification and item reduction was completed based on the removal of items demonstrating factor loadings below 0.5. Five subscales based on 15 items with significant factor loadings were produced through the principle component analysis process (see Tables 2 and 3 ).

The five-factor structure accounted for 58.61 per cent of the variance with Cronbach's $\alpha$ score of 0.726. The factors (dimensions) were labelled as follows: factor 1, cultural empathy (22.19 per cent); factor 2, cultural uncertainty (11.59 per cent); factor 3, communication bias (9.18 per cent); factor 4, communication engagement ( 8.19 per cent) and factor 5, interpersonal skills ( 7.18 per cent). These names were selected based on the item distribution by Matveev and Nelson (2004) and are consistent with their CCC model. Three of the factor groupings were in line with those produced by Matveev and Nelson (2004), while the fourth factor, namely 'team effectiveness' was split into two factor groupings, communication bias and communication engagement. The rotated factor structure for the CCC questionnaire is presented in Table 3. The factor score for each component was developed reflecting each individual respondents' score on each of the item subsets. By using the Anderson-Rubin method, uncorrelated factor scores were produced and the data was protected against multicollinearity (Tabachnick and Fidell, 2007). A total score was then created by adding the factor scores all together.

\section{Principle component analysis of CEQS data}

Upon conducting principal component analysis of the CEQS data, two distinct factors (dimensions) were produced (see Table 4). The KMO test was used to measure the data adequacy and produced a high score of 0.939 . The two subscales represented by the factors comprised 17 items with significant factor loadings.

The total variance accounted for by these two factors was 66.14 per cent with a Cronbach's $\alpha$ score of 0.954 . The names of the factors and the amount of variance each accounted for are as follows: factor 1 , team effectiveness (59.21 per cent) and factor 2, performance ability, aka the 'hard 
Table 3. Rotated factor matrix for CCC questionnaire data.

\begin{tabular}{|c|c|c|c|c|c|c|}
\hline \multirow[b]{2}{*}{ Dimensions } & \multirow[b]{2}{*}{ Item description } & \multicolumn{5}{|c|}{ Factor } \\
\hline & & I & 2 & 3 & 4 & 5 \\
\hline \multirow[t]{4}{*}{$\begin{array}{l}\text { Cultural } \\
\text { empathy }\end{array}$} & $\begin{array}{l}\text { I am flexible when working with people from different } \\
\text { cultures as I acknowledge differences in values and } \\
\text { beliefs among cultures }\end{array}$ & 0.745 & & & & \\
\hline & $\begin{array}{l}\text { Viewing people from their cultural perspectives is } \\
\text { helpful when working on a multicultural team }\end{array}$ & 0.697 & & & & \\
\hline & $\begin{array}{l}\text { Working effectively with other people involves } \\
\text { understanding other peoples' beliefs }\end{array}$ & 0.635 & & & & \\
\hline & $\begin{array}{l}\text { Working with people from different cultures is } \\
\text { exciting }\end{array}$ & 0.541 & & & & \\
\hline \multirow[t]{3}{*}{$\begin{array}{l}\text { Cultural } \\
\text { uncertainty }\end{array}$} & $\begin{array}{l}\text { Establishing a good working relationship with people } \\
\text { from other countries is difficult* }\end{array}$ & & 0.825 & & & \\
\hline & $\begin{array}{l}\text { Dealing with and managing cultural uncertainties is } \\
\text { troublesome* }\end{array}$ & & 0.791 & & & \\
\hline & $\begin{array}{l}\text { Dealing with cultural differences is a frustrating } \\
\text { process* }\end{array}$ & & 0.700 & & & \\
\hline \multirow[t]{3}{*}{$\begin{array}{l}\text { Communication } \\
\text { bias }\end{array}$} & $\begin{array}{l}\text { Effectiveness of communication on the team falls when } \\
\text { people from different countries are working on the } \\
\text { team* }\end{array}$ & & & 0.771 & & \\
\hline & $\begin{array}{l}\text { Information sharing in my team decreases if people } \\
\text { from different cultures are present* }\end{array}$ & & & 0.604 & & \\
\hline & $\begin{array}{l}\text { Hearing people speaking with an accent makes me } \\
\text { believe that they are less capable* }\end{array}$ & & & 0.558 & & \\
\hline \multirow{2}{*}{$\begin{array}{c}\text { Communication } \\
\text { engagement }\end{array}$} & I listen actively to other people in my team & & & & 0.695 & \\
\hline & $\begin{array}{l}\text { I engage in a meaningful dialogue with people from } \\
\text { other countries in the same way as with people } \\
\text { from my own country }\end{array}$ & & & & .661 & \\
\hline \multirow[t]{3}{*}{$\begin{array}{l}\text { Interpersonal } \\
\text { skills }\end{array}$} & $\begin{array}{l}\text { I work with nationals from other countries differently } \\
\text { from the way I work with people from my home } \\
\text { country* }\end{array}$ & & & & & 0.693 \\
\hline & $\begin{array}{l}\text { I feel uncomfortable working with people from } \\
\text { different countries* }\end{array}$ & & & & & 0.638 \\
\hline & $\begin{array}{l}\text { My team involves every member in the decision- } \\
\text { making process without any relevance to the } \\
\text { national origin of a team member }\end{array}$ & & & & & 0.514 \\
\hline
\end{tabular}

Note: Extraction method is principle component analysis. Rotation method is varimax with Kaiser normalization. *Items in these sections are reversed scored.

skills' of the basketball players (6.93 per cent). These names describe the general sense behind the factors and are consistent with the components of efficacy theories of Bandura $(1997,2001)$ and Short et al. (2005). The factor score for each component was developed (again by using the Anderson-Rubin method to produce uncorrelated factor scores) (Tabachnick and Fidell, 2007). The rotated factor structure for the CEQS data is presented in Table 5. 
Table 4. Total variance explained in principle component analysis of scale items measuring collective efficacy.

\begin{tabular}{lccccccc}
\hline & \multicolumn{3}{c}{ Initial eigenvalues } & & \multicolumn{2}{c}{ Rotation sums of squared loadings } \\
\cline { 2 - 4 } Factor & Total & Per cent of variance & $\begin{array}{c}\text { Cumulative } \\
\text { per cent }\end{array}$ & & Total & Per cent of variance & Cumulative per cent \\
\hline 1 & 10.066 & 59.212 & 59.212 & 8.229 & 48.404 & 48.404 \\
2 & 1.177 & 6.925 & 66.136 & 3.014 & 17.732 & 66.136 \\
\hline
\end{tabular}

Note: Extraction method is principle component analysis.

Table 5. Rotated factor matrix for CEQS data.

\begin{tabular}{|c|c|c|c|}
\hline \multirow[b]{2}{*}{ Dimensions } & \multirow[b]{2}{*}{ Item description } & \multicolumn{2}{|c|}{ Factor } \\
\hline & & I & 2 \\
\hline \multirow[t]{14}{*}{ Team effectiveness } & Maintain effective communication & 0.840 & \\
\hline & Overcome distractions & 0.822 & \\
\hline & Stay in the game when it seems like your team isn't getting any breaks & 0.799 & \\
\hline & Keep a positive attitude & 0.786 & \\
\hline & Persist when obstacles are present & 0.782 & \\
\hline & Play to its capabilities & 0.778 & \\
\hline & Demonstrate a strong work ethic & 0.767 & \\
\hline & Mentally prepare for the competition & 0.757 & \\
\hline & Show enthusiasm & 0.743 & \\
\hline & Be united & 0.733 & \\
\hline & Devise a successful strategy & 0.700 & \\
\hline & Physically prepare for the competition & 0.679 & \\
\hline & Resolve conflicts & 0.646 & \\
\hline & Play well without your best player & 0.639 & \\
\hline \multirow[t]{3}{*}{ Performance ability } & Show more ability than the other teams & & 0.864 \\
\hline & Play more skilfully than the opponent & & 0.809 \\
\hline & Outplay the opposing teams & & 0.623 \\
\hline
\end{tabular}

Note: Extraction method is principle component analysis. Rotation method is varimax with Kaiser normalization.

*Items are reversed score.

Common method variance could be a concern in research wherein self-reported research results are artificially skewed because the respondents share biases that impact the measurement of the variables. Spector (2006) argued that common method variance produces significant correlations between variables. Using this rationale, Elias (2009) looked for multicollinearity to determine if enough correlation existed among variables to indicate common method variance. For this study, principle component analysis was able to produce distinct factors from the items, which indicates limited multicollinearity between items (Table 5).

\section{Regression analysis}

Regression analysis was conducted to explore the relationship between both the total cross-cultural communication competence score and the total collective efficacy score and between the individual 
Table 6. Cross-cultural communication regression statistics for team effectiveness.

\begin{tabular}{lcccc}
\hline CCC dimensions & SE & $\beta$ & $t$ & Significance \\
\hline Cultural empathy & 0.075 & 0.176 & 2.339 & $0.021^{*}$ \\
Cultural uncertainty & 0.075 & 0.301 & 3.995 & $0.000^{*}$ \\
Communication bias & 0.075 & 0.294 & 3.911 & $0.000^{*}$ \\
Communication engagement & 0.075 & 0.172 & 2.291 & $0.024^{*}$ \\
Interpersonal skills & 0.075 & 0.059 & 0.790 & 0.431 \\
\hline
\end{tabular}

*Significant at a 95 per cent confidence level.

Table 7. Cross-cultural communication regression statistics for performance ability.

\begin{tabular}{lcrrc}
\hline CCC dimensions & SE & \multicolumn{1}{c}{$\beta$} & \multicolumn{1}{c}{$t$} & Significance \\
\hline Cultural empathy & 0.085 & 0.124 & 1.456 & 0.148 \\
Cultural uncertainty & 0.085 & -0.056 & -0.663 & 0.509 \\
Communication bias & 0.085 & 0.114 & 1.336 & 0.184 \\
Communication engagement & 0.085 & -0.021 & -0.251 & 0.802 \\
Interpersonal skills & 0.085 & 0.016 & 0.187 & 0.852 \\
\hline
\end{tabular}

*Significant at a 95 per cent confidence level.

CCC factor scores (cultural empathy, cultural uncertainty, communication bias, communication engagement and interpersonal skills), and the two individual factor scores of collective efficacy (team effectiveness and performance ability).

The results indicated that there was a significant positive relationship between total cross-cultural communication competence and total collective efficacy at a 95 per cent confidence level. The total cross-cultural communication competence is able to explain 14.3 per cent $\left(R^{2}\right)$ of the variance within the total collective efficacy score.

Further analysis was undertaken to determine which factors within cross-cultural communication competence were most influential in predicting the two dimensions of collective efficacy (team effectiveness and performance ability). It could be expected that team effectiveness dimension of collective efficacy could be influenced more by the coaches CCC than the performance ability dimension. The performance ability dimension reflects the team's actual ability and skillfulness, while the team effectiveness dimension reflects the teams overall attitude, communication, preparation and teamwork, all of which can potentially be influenced by the coach.

It was found in this research that the individual cultural empathy, cultural uncertainty, communication bias and communication engagement factors are all statistically able to predict a rise in team effectiveness at a 95 per cent confidence level. As the scores for cultural empathy, cultural uncertainty, communication bias and communication engagement increased, so did the score for team effectiveness. However, the interpersonal skills factor was not statistically linked at a 95 per cent confidence level to an increase or decrease in the team effectiveness variable (see Table 6). The model produced, after the removal of the interpersonal skills factor, was able to explain 21.5 per cent (adjusted $R^{2}$ ) of the variance in the team effectiveness variable.

None of the five factors produced from the CCC questionnaire were statistically able to predict a rise or decline in the performance ability variable developed from the CEQS (see Table 7). 


\section{Discussion}

The results of the data analysis support the hypothesis that cross-cultural communication competence of NCAA basketball coaches positively impacts their team's collective efficacy. To gain a deeper insight into the impact of cross-cultural communication on collective efficacy, the dimensions within cross-cultural communication competence were analysed against the individual collective efficacy dimensions.

This further analysis highlighted that cross-cultural communication competence has an impact on team effectiveness, one of the two dimensions produced from the CEQS. Increases in four of the dimensions in the cross-cultural communication competence of NCAA basketball coaches were found to be related and able to predict an increase in team effectiveness when working with multicultural basketball teams. These CCC dimensions are consistent with the reviewed literature on cross-cultural communication competence in business and management, including Ruben's (1976), Abe and Wiseman's (1983), Cui and Awa's (1992) and Matveev's (2002) models, and serve as a new template model for research into cross-cultural communication and multicultural sport team coaching. The relationship was statistically confirmed and measured, concluding that these four dimensions of cross-cultural communication competence account for 21.5 per cent of the variance in team effectiveness.

While the hypothesis was correct that cross-cultural communication competence positively impacts collective efficacy, further analysis reveals that some aspects of collective efficacy were not statistically impacted. The 'performance ability' dimension of collective efficacy cannot be predicted by a sporting coach's cross-cultural communication competence. This result could seem intuitive; performance ability involves individual athletic skills and talents largely external to the information sought by this study. However, Duck (1993) found that, during competition, players' understanding of the coach's messages regarding tactics and strategies is crucial for effective performance. Due to the competitive nature of NCAA recruitment, it can be assumed that many of the players are near their physical peak when they are recruited and many strive to remain that way in order to be recruited. The youth and short-term nature of the NCAA teams may be a reason that the relationship with performance ability was not stronger, despite the Duck (1993) findings.

Similarly, not all of the CCC factors impacted collective efficacy in the same fashion. The interpersonal skills CCC factor was not linked to a change in collective efficacy. While Matveev and Nelson (2004) found that this factor was linked to the communication engagement factor, in this study, the two disassociated and impacted collective efficacy differently. In this study, communication engagement involved actively listening and engaging with individuals from other countries, while interpersonal skills looked at how equally the respondent worked with and involved individuals from other countries in the team and decision-making process. Further study would be needed to understand why the factors broke down in such a manner; it could be that some language/ communication barriers emerge in high-stress team settings that make it harder for a coach to work with all team members equally.

This study shows that the role of the coach as an effective manager and communicator is especially important in an NCAA basketball team setting. Due to the terminal nature of college sports careers (and NCAA regulations capping the number of years a student may play), the best player on the team will eventually graduate and leave the team. A high-performing teammate's departure in any setting is disruptive to a team's collective confidence in its effectiveness and may be that much more so when the team members are young and the player is a 'superstar' on campus (Bandura, 1997). A coach's cross-cultural communication competence must overcome the losses 
due to performance ability and a team members' questioning of their ability upon a teammate's departure.

Similarly, a coach must use his management skills to help team members spring back after defeats on the court, which can also lower a team's collective efficacy. The relationship between cross-cultural communication competency and the team effectiveness dimension of collective efficacy is enlightening in this scenario. This study shows that the coach can have an impact on collective efficacy, and thus on team performance, in light of defeats or player turnover resulting in overall lowering of performance ability.

Sporting coaches often refer to communication as a key skill necessary to effectively coach a team (Parcells and Coplon, 1995; Shanahan, 1999). This study has shown that effective communication across cultures is an important component of team effectiveness, that is, the team's ability to operate cohesively, and further, has the ability to enhance team effectiveness in light of setbacks due to the performance ability or hard skills of a team. Although the 2014 Maderer et al.'s study found that a coaches' intercultural coaching experience negatively impacted the teams' performance, the study did not examine the coaches' cross-cultural communication competency, only their experience, which may not be a proxy for their ability to communicate across cultures. Furthermore, the study was completed on (European) football teams, a sport that has a strong cultural component to the way it is played in different countries (Ruigrok et al., 2011), thus meaning that intercultural coaching experience may indicate experience with a different playing style, which may have mixed effects on a subnational-level team.

The results produced in this study through regression analysis are consistent with research that linked cross-cultural communication competence and team performance in a business setting (Matveev and Nelson, 2004). Similarly, Himstreet (1977) put forth communication as an important predictor of team effectiveness and efficiency in businesses. Existing literature also supports a relationship between a business manager's communication competence and team performance (Ancona and Caldwell, 1992; Smith et al., 1994). Whether the findings of this study are applicable to business organizations is beyond the scope of this study. Existing literature shows a significant overlap between business management and sporting teams coaching and management (Weinberg and McDermott, 2002), with studies using basketball teams to draw conclusions for wider organizations behaviour (e.g. Berman et al., 2002; Pfeffer and Davis-Blake, 1986; Staw and Hoang, 1995). Implications would most likely apply to teams that, like basketball teams, have a high degree of interaction and interdependency among members (Keidel, 1985).

In business, clear lines of communication between management and employees have been frequently highlighted as critical to the achievement of organizational success (Blundel and Ippolito, 2008). Further research could unpack the similarities between cross-cultural communication competency on organizational collective efficacy and determine if, indeed, collective efficacy breaks down into the same dimensions in the business world, and if a manager's cross-cultural communication competency affects these dimensions similarly.

This study demonstrates that, when working with a multicultural team, a sporting coach's ability to communicate effectively with individuals who have different cultural backgrounds increases overall collective efficacy and enhances the team effectiveness element of the team's collective efficacy.

\section{Conclusions and implications}

Doherty and Chelladurai (1999) argue that the effective management of cultural diversity is critical in sports organizations, not only for their success but also their survival, because of their need to tap 
into human resources. This research contributes to knowledge and theory of the fields of crosscultural communication competence, collective efficacy, multicultural team development and intercultural sport team management. It confirms the relevance of cross-cultural communication competence in sports management and its effect on coaching multicultural sporting teams while revealing its limitations, particularly on performance ability. As sporting teams are perpetually seeking ways to enhance performance and boost scores, this study suggests that cross-cultural communication competence is a relevant issue for sporting coaches and managers to address, as its effective implementation in an overall management strategy can enhance collective efficacy overall and overcome potential shortcomings due to the team's raw talent. The study also revealed that not all cross-cultural communication competence aspects impact collective efficacy equally, revealing that aspects of cross-cultural communication competence need to be assessed to be fit for purpose and setting.

Additionally, the dimensions produced from the principle component analysis on the CCC questionnaire can all be improved and developed with proper training. This could result in an improvement of the training tools for the development of sporting coaches of multicultural teams within educational institutions, as currently only 53 per cent of NCAA athletic departments offer diversity training (Cunningham, 2012). Universities have increased interest in developing curricula that include cross-cultural understanding and knowledge over the last decade, meaning that this information would be timely and relevant (Derkun et al., 2010). As many Western universities recruit internationally in order to bring crucial operating revenue, and as organizations such as the NCAA increase their focus on diversity, the need for effective cross-cultural communication competency at a university level will continue to increase in importance.

Past research has been supportive of a direct link between cross-cultural communication competence and business team performance (Matveev and Nelson, 2004). This study demonstrates that the link between cross-cultural communication competence and collective efficacy is both relevant and important not only to the development of businesses but also to developing more effective multicultural collegiate sporting teams.

\section{Limitations}

Responses could have been affected by social desirability effects, which occur 'when respondents give the culturally acceptable response rather than describing what they actually think about the topic at hand' (Simkhovych, 2009: 389). Research has shown this phenomenon to be present in surveys asking about multiculturalism, immigration and cultural diversity (Dandy and Pe-Pua, 2010). Nevertheless, the use of computer-based self-administered questionnaires and the assured confidentiality of responses diminished the risk of social desirability bias. Single respondent bias could have occurred as a result of one individual from each team answering the questionnaire. However, the relatively flat management structure of the NCAA teams means that head coaches provide best perspective on the teams.

It is unclear whether the results are applicable across other team sports. Different levels of interdependency and differing roles of coaches across sports teams make it difficult to apply these results across other sports or organizational teams without a high degree of interaction and interdependency among members (Keidel, 1985). While basketball has not been shown to have the same cross-national differences in play of European football, further study would be necessary to understand if the results carry in other countries. 


\section{Future research}

Future studies could include outcome-based data to reduce bias from self-reported surveys and interviews with a sample of the survey participants to discern the drivers behind the data results and add depth to the data. Future research could also expand the participant population within the CEQS to include team members in addition to the coaches. This research is based on the perceptions of the participant coaches within the NCAA basketball divisions rather than individual team members. However, the coaches might be in the best position to consider their teams from a macro level rather than the individual players.

Finally, further research may be required to determine the impact in other sporting areas where the team size and level of interdependence between the team members differ (Sakuda, 2012; Timmerman, 2000) to understand whether the results can be transferred to other team settings. According to the existing literature, the impact of cross-cultural communication competence on the collective efficacy of multicultural teams will vary across different sports depending on the level of task interdependence, as well as preference for management style. The CEQS is specially designed to allow the comparison of confidence levels within and across sports, making further research in this direction possible (Short et al., 2005).

\section{Declaration of conflicting interests}

The author(s) declared no potential conflicts of interest with respect to the research, authorship, and/or publication of this article.

\section{Funding}

The author(s) received no financial support for the research, authorship, and/or publication of this article.

\section{References}

Abe H and Wiseman RL (1983) A cross cultural confirmation of the dimensions of intercultural effectiveness. International Journal of Intercultural Relations 7(1): 53-67.

Ancona DG and Caldwell DF (1992) Demography and design: predictors of new product team performance. Organization Science 3(3): 321-41.

Andresen M and Altmann T (2006) Diversity und Erfolg im Profifussball. Zeitschrift Führung + Organisation: ZfO 75(6): 325-32.

Bandura A (1997) Self-Efficacy: The Exercise of Control. New York: Worth Publishers.

Bandura A (2001) Social cognitive theory: an agentic perspective. Annual Review of Psychology 52(1): 1-26.

Bell ST (2007) Deep-level composition variables as predictors of team performance: a meta-analysis. Journal of Applied Psychology 92(3): 595-615.

Berman SL, Down J, and Hill CW (2002) Tacit knowledge as a source of competitive advantage in the National Basketball Association. Academy of Management Journal 45(1): 13-31.

Black JS and Gregersen HB (1999) The right way to manage expats. Harvard Business Review 77(2): 52.

Blasco M, Egholm Feldt L, and Jakobsen M (2012) If only cultural chameleons could fly too: a critical discussion of the concept of cultural intelligence. International Journal of Cross Cultural Management 12(2): 229-45.

Blundel R and Ippolito K (2008) Effective Organisational Communication: Perspectives, Principles and Practices. England: Prentice Hall.

Brandes L, Franck E, and Theiler P (2009) The effect from national diversity on team production: empirical evidence from the sports industry. Schmalenbach Business Review 61: 225-46.

Campion MA, Papper EM, and Medsker GJ (1996) Relations between work team characteristics and effectiveness: a replication and extension. Personnel Psychology 49(2): 429-52. 
Chang SJ, Van Witteloostuijn A, and Eden L (2010). From the editors: common method variance in international business research. Journal of International Business Studies 41(2): 178-84.

Chapman KJ and Van Auken S (2001) Creating positive group project experiences: an examination of the role of the instructor on students' perceptions of group projects. Journal of Marketing Education 22(2): $117-27$.

Chelladurai P, Malloy D, Imamura H, et al. (1987) A cross cultural study of preferred leadership in sports. Canadian Journal of Sport Sciences 12: 106-10.

Chelladurai P, Imamura H, Yamaguchi Y, et al. (1988) Sport leadership in a cross-national setting: the case of Japanese and Canadian university athletes. Journal of Sport \& Exercise Psychology 10(4): 374-89.

Chen G and Bliese PD (2002) The role of different levels of leadership in predicting self- and collective efficacy: evidence for discontinuity. The Journal of Applied Psychology 87(3): 549-56.

Chevrier S (2009) Is national culture still relevant to management in a global context? The case of Switzerland. International Journal of Cross Cultural Management 9(2): 169-83.

Chmielecki M (2012) Teaching intercultural communication in Polish higher education management programmes - a critical look. Journal of Intercultural Management 4(4): 79-89.

Congden SW, Matveev AV, and Desplaces DE (2009) Cross cultural communication and multicultural team performance: a German and American comparison. Journal of Comparative International Management 12 (2): 73-89.

Cox TH (1994) Cultural Diversity in Organizations: Theory, Research, and Practice. San Francisco: BenettKoehler Publishers.

Cui G and Awa NE (1992) Measuring intercultural effectiveness: an integrative approach. International Journal of Intercultural Relations 16(3): 311-328.

Cunningham GB (2012) Diversity training in intercollegiate athletics. Journal of Sport Management 26(5): 391-403.

Dandy J and Pe-Pua R (2010) Attitudes to multiculturalism, immigration and cultural diversity: comparison of dominant and non-dominant groups in three Australian states. International Journal of Intercultural Relations 34(1): 34-46.

Deardorff DK (2011) Assessing intercultural competence. New Directions for Institutional Research 149(149): 65-79.

Derkun CA, Rayuskaya TO, and Kresova NS (2010) Cross cultural communication. European Researcher 1 (1): 74-77.

Dirks T (2000) Trust in leadership and team performance: evidence from NCAA basketball. Journal of Applied Psychology 85(6): 1004-12.

Doherty AJ and Chelladurai P (1999) Managing cultural diversity in sport organizations: a theoretical perspective. Journal of Sport Management 13(4): 280-97.

Duck S (1993) Communication and Relational Maintenance. San Diego: Academic Press.

Elias SM (2009) Employee commitment in times of change: assessing the importance of attitudes toward organizational change. Journal of Management 35(1): 37-55.

Ely RJ and Thomas DA (2001) Cultural diversity at work: the effects of diversity perspectives on work group processes and outcomes. Administrative Science Quarterly 46(2): 229-73.

Gaede N, Kleist S, and Schaecke M (2002) "Elf Freunde müsst ihr sein?": Die strategische Entscheidung der Teamzusammensetzung. In: Schewe G and Littkemann J (eds) Sportmanagement. Der Profi-Fußball aus Sportökonomischer Perspektive. Schorndorf, Heilbronn: Karl Hofmann, pp. 213-42.

Gibson CB (1999) Do they do what they believe they can? Group efficacy and group effectiveness across tasks and cultures. Academy of Management Journal 42(2): 138-52.

Gong Y, Shenkar O, Luo Y, et al. (2001) Role conflict and ambiguity of CEOs in international joint ventures: a transaction cost perspective. Journal of Applied Psychology 86(4): 764-73.

Greenlees IA, Graydon JK, and Maynard IW (1999) The impact of collective efficacy beliefs on effort and persistence in a group task. Journal of Sports Sciences 17(2): 151-58. 
Gudykunst WB (1997) Cultural variability in communication: an introduction. Communication Research 24 (4): 327-348.

Gudykunst WB (1998) Applying anxiety/uncertainty management (AUM) theory to intercultural adjustment training. International Journal of Intercultural Relations 22(2): 227-50.

Gully SM, Incalcaterra KA, Joshi A, et al. (2002) A meta-analysis of team-efficacy, potency, and performance: interdependence and level of analysis as moderators of observed relationships. The Journal of Applied Psychology 87(5): 819-32.

Hall ET (1959) The Silent Language. Garden City: Anchor Books.

Heuzé J-P, Raimbault N, and Fontayne P (2006) Relationships between cohesion, collective efficacy and performance in professional basketball teams: an examination of mediating effects. Journal of Sports Sciences 24(1): 59-68.

Himstreet WC (1977) Business Communications: Principles and Methods. Belmont: Wadsworth Publishing Company.

Hofstede G (1980) Culture's consequences: International Differences in Work-Related Value. Thousand Oaks: SAGE.

Hurn B and Tomalin B (2013) Cross-Cultural Communication: Theory and Practice. London: Palgrave Macmillan.

Joshi A and Roh H (2009) The role of context in work team diversity research: a meta-analytic review. Academy of Management Journal 52(3): 599-627.

Kaiser HF (1960) The application of electronic computers to factor analysis. Educational and Psychological Measurement 20: 141-51.

Kaiser HF (1974) An index of factorial simplicity. Psychometrika 39(1): 31-6.

Kalmi P and Sweins C (2010) The performance impact of financial participation: subjective and objective measures compared. In: Kato T (ed), Advances in the Economic Analysis of Participatory \& LaborManaged Firms. Bingly: Emerald Group Publishing Limited, pp. 69-88.

Katz-Navon TY and Erez M (2005) When collective- and self-efficacy affect team performance: the role of task interdependence. Small Group Research 36(4): 437-65.

Keidel RW (1985) Game Plans: Sports Strategies for Business. Moston: EP Dutton.

Kieffer L (1997) Building a Team. Madison: Nonprofit World.

Kumar N, Stern LW, and Anderson JC (1993) Conducting interorganizational research using key informants. Academy of Management Journal 36(6): 1633-51.

Lane HW, Maznevski MK, Mendenhall ME, et al. (2004) The Blackwell Handbook of Global Management: A Guide to Managing Complexity. Oxford: Blackwell Publishers.

Larson CE and Lafasto FMJ (1989) Teamwork: What must go Right, What can go Wrong. London: SAGE.

Levy O, Beechler S, Taylor S, and Boyacigiller NA (2007) What we talk about when we talk about 'global mindset': managerial cognition in multinational corporations. Journal of International Business Studies 38 (2): $231-58$.

Lindell MK and Whitney DJ (2001) Accounting for common method variance in cross-sectional research designs. Journal of Applied Psychology 86(1): 114-21.

Maderer D, Holtbrügge D, and Schuster T (2014) Professional football squads as multicultural teams: cultural diversity, intercultural experience, and team performance. International Journal of Cross Cultural Management 14(2): 215-38.

MacNab BR and Worththley R (2013) Stereotype awareness development and effective cross cultural management. International Journal of Cross Cultural Management 13(1): 65-87.

Madlock PE (2008) The link between leadership style, communicator competence, and employee satisfaction. Journal of Business Communication 45(1): 61-78.

Magyar TM, Feltz DL, and Simpson IP (2004) Individual and crew level determinants of collective efficacy in rowing. Journal of Sport \& Exercise Psychology 26(1): 136-53.

Majahan A and De Silva SR (2012) Unmet role expectations of expatriates, host-country national support, and expatriate adjustment. International Journal of Cross Cultural Management 12(3): 349-60. 
Mannix E and Neale MA (2005) What differences make a difference? Psychological Science in the Public Interest 6(2): 31-55.

Matveev AV (2002) The perception of intercultural communication competence by American and Russian managers with experience on multicultural teams $\mathrm{PhD}$ Thesis, Ohio University, Athens, $\mathrm{OH}$, USA.

Matveev AV and Nelson PE (2004) Cross cultural communication competence and multicultural team performance perceptions of American and Russian managers. International Journal of Cross Cultural Management 4(2): 253-70.

Mor S, Morris MW, and Joh J (2013) Identifying and training adaptive cross cultural management skills. Academy of Management Learning \& Education 12(3): 453-75.

Mor-Barak ME (2011) Managing Diversity: Toward a Globally Inclusive Workplace. Los Angeles: Sage Publications.

Myers ND, Feltz DL, and Short SE (2004) Collective efficacy and team performance: a longitudinal study of collegiate football teams. Group Dynamics: Theory, Research, and Practice 8(2): 126-38.

National Collegiate Athletic Association [NCAA] (2015a) Sport Sponsorship, Participation and Demographics Search [Data file]. Retrieved from http://web1.ncaa.org/rgdSearch/exec/main (accessed 24 June 2015).

National Collegiate Athletic Association [NCAA] (2015b) NCAA Eligibility Toolkit. Available at: http://www. ncaa.org/student-athletesresources/division-i-initial-eligibility-toolkit (accessed 1 August 2015).

Nixon JC and Dawson GA (2002) Reason for cross cultural communication training. Corporate Communications: An International Journal 7(3): 184-91.

O'Reilly III CA, Caldwell DF, and Barnett WP (1989) Work group demography, social integration, and turnover. Administrative Science Quarterly 34: 21-37.

Orfield G (2009) Reviving the Goal of an Integrated Society: A 21st Century Challenge: Report. USA: University of California. Available at: http://escholarship.org/uc/item/2bw2s608 (accessed 25 July 2015).

Parcells B and Coplon J (1995) Finding a Way to Win: The Principles of Leadership, Teamwork, and Motivation. New York: Doubleday.

Parkhe A (1993) Strategic alliance structuring: a game theoretic and transaction cost examination of interfirm cooperation. Academy of Management Journal 36: 794-829.

Pfeffer J and Davis-Blake A (1986) Administrative succession and organizational performance: how administrator experience mediates the succession effect. Academy of Management Journal 29(1): 72-83.

Plessis Y (2012) Exploring teamwork paradoxes challenging 21st-century cross cultural conflict management in a multicultural organizational context. International Journal of Cross Cultural Management 12(1): 49-71.

Podsakoff PM, MacKenzie SB, Lee JY, et al. (2003) Common method biases in behavioral research: a critical review of the literature and recommended remedies. Journal of Applied Psychology 88(5): 879-903.

Prinz J and Wicker P (2012) Team and individual performance in the Tour de France. Team Performance Management: An International Journal 18(7/8): 418-32.

Ramzaninezhad R, Keshtan MH, Shahamat MD, et al. (2009) The relationship between collective efficacy, group cohesion and team performance in professional volleyball teams. Brazilian Journal of Biomotricity 3 (1): 31-9.

Ricard VB (1993) Developing Intercultural Communication Skills. Malabar: Krieger Publishing Company.

Ruben B (1976) Human communication and cross cultural effectiveness. International and Intercultural Communication Journal 4: 95-105.

Ruigrok W Greve P and Engeler M (2011) International experiential diversity and performance at project organizations: the case of national football teams. Sport, Business and Management: An International Journal 1(3): 267-83.

Sakuda KH (2012) National diversity and team performance in low interdependence tasks. Cross Cultural Management: An International Journal 19(2): 125-41.

Schriesheim CA and Hill KD (1981) Controlling acquiescence response bias by item reversals: the effect on questionnaire validity. Educational and Psychological Measurement 41(4): 1101-14. 
Shanahan M (1999) Think Like a Champion: Building Success One Victory at a Time. New York: Harper Collins.

Shonk JH (1982) Working in Teams: A Practical Manual for Improving Work Groups. New York: Amacom.

Short SE, Sullivan P, and Feltz DL (2005) Development and preliminary validation of the collective efficacy questionnaire for sports. Measurement in Physical Education and Exercise Science 9(3): 181-202.

Simkhovych D (2009) The relationship between intercultural effectiveness and perceived project team performance in the context of international development. International Journal of Intercultural Relations 33 (5): 383-90.

Smith KG, Smith KA, Olian JD, et al. (1994) Top management team demography and process: the role of social integration and communication. Administrative Science Quarterly 39(3): 412-38.

Spector PE (2006) Method variance in organizational research: truth or urban legend? Organizational Research Methods 9: 221-32.

Stahl GK, Maznevski ML, Voigt A, et al. (2010) Unraveling the effects of cultural diversity in teams: a metaanalysis of research on multicultural work groups. Journal of International Business Studies 41(4): 690-709.

Staw BM and Hoang H (1995) Sunk costs in the NBA: why draft order affects playing time and survival in professional basketball. Administrative Science Quarterly 40(3): 474-94.

Stockdale MS and Crosby FJ (2004) The Psychology and Management of Workplace Diversity. Malden: Blackwell Publishing.

Tabachnick BG and Fidell LS (2007) Using Multivariate Statistics, 5th ed. New York: Allyn and Bacon.

Tajfel H (1982) Social psychology of intergroup relations. Annual Review of Psychology 33: 1-39.

Teichmann K (2007) Strategie und Erfolg von Fußballunternehmen. Wiesbaden: Deutscher Universitäts-Verlag.

Timmerman TA (2000) Racial diversity, age diversity, interdependence, and team performance. Small Group Research 31(5): 592-606.

Tourangeau R and Rasinski KA (1988) Cognitive processes underlying context effect in attitude measurement. Psychological Bulletin 103: 299-314.

Triandis HC and Singelis TM (1998) Training to recognize individual differences in collectivism and individualism within culture. International Journal of Intercultural Relations 22(1): 35-47.

Tung RL (2008) The cross cultural research imperative: the need to balance cross-national and intra-national diversity. Journal of International Business Studies 39(1): 41-6.

Van Der Zee K, Atsma N, and Brodbeck F (2004) The influence of social identity and personality on outcomes of cultural diversity in teams. Journal of Cross cultural Psychology 35(3): 283-303.

Watson CB, Chemers MM, and Preiser N (2001) Collective efficacy: a multilevel analysis. Personality and Social Psychology Bulletin 27(8): 1057-68.

Weick KE and Roberts KH (1993) Collective mind in organizations: heedful interrelating on flight decks. Administrative Science Quarterly 38(3): 357-81.

Weinberg R and McDermott M (2002) A comparative analysis of sport and business organizations: factors perceived critical for organizational success. Journal of Applied Sport Psychology 14(4): 282-98.

Wheelan SA (1999) Creating Effective Teams: A Guide for Members and Leaders. Thousand Oaks: SAGE.

Wheelan SA, Buzaglo G, and Tsumura E (1998) Developing assessment tools for cross cultural group research. Small Group Research 29(3): 359-70.

Williams KY and O'Reilly CA (1998) Demography and diversity in organizations: a review of 40 years of research. Research in Organizational Behavior 20: 77-140.

Wiseman RL, Hammer MR, and Nishida H (1989) Predictors of intercultural communication competence. International Journal of Intercultural Relations 13(3): 349-70.

Wright PM, Smart DL, and McMahan GC (1995) Matches between human resources and strategy among NCAA basketball teams. The Academy of Management Journal 38(4): 1052-74.

Wulf T and Hungenberg H (2006) Erfolg von Fußball-Bundesligavereinen-eine Empirische Analyse des Beitrags von Mannschaft, Trainer und Sportmanager. Working paper, pp. 1-27. Available at: http://www. 
management.wiso.uni-erlangen.de/Forschung/Arbeitspapiere/IUP AP 06-01 Erfolg von Fuball-Bundesli gavereinen.pdf (accessed 29 June 2016).

Yukelson D (1997) Principles of effective team building interventions in sport: a direct services approach at Penn State University. Journal of Applied Sport Psychology 9(1): 73-96.

Yukl GA (2012) Leadership in Organizations. Upper Saddle River: Prentice Hall. 